\title{
SPINAL ANAESTHESIA IN THE PRESENCE OF GROSS SPINAL DEFORMITY
}

\author{
Shiraz Walj and Gerald B.H. Lewis *
}

The PROS AND CONS of spinal anaesthesia have been hotly debated. Be this as it may, the patient's expressed wish to retain consciousness is a valid indication for any kind of regional anaesthetic technique.

In the following case the patient's desire to remain conscious during operation was fulfilled despite gross spinal deformity which had made us hesitate to attempt spinal anaesthesia.

\section{Case Repont}

Mr. H. L., a white male, aged 62 and weighing 117 pounds, was admitted with the intention to correct anal stenosis by anoplasty. He was paraplegic due to anterior poliomyelitis in childhood leading to severe kyphoscoliosis. He had suffered diabetes mellitus for four years which was controlled by chlorpropamide $125 \mathrm{mg}$ daily. Chronic obstructive pulmonary disease had developed over the years and he had smoked an average of 20 cigarettes daily for the past 44 years.

On examination the positive findings were gross spinal deformity with kyphoscoliosis and paraplegia. The thoraco-lumbar spine was affected most as may be seen from Figures 1 and 2. The trachea was deviated to the left, the chest was hyperresonant on percussion and clear to auscultation. Preoperative investigation revealed a haemoglobin of 13.8 grams per cent, fasting blood sugar of 94 milligrams per cent; serum electrolytes and other blood serum values were normal. Chest $\mathrm{X}$-ray confirmed marked thoracolumbar kyphoscoliosis convex to the left. Pulmonary function studies showed forced expiratory volume in one second $\left(\mathrm{FEV}_{1}\right)$ to be 60 per cent, and Vital Capacity (V.C.) 2.06 litres or 46 per cent of predicted value but this improved with bronchodilators to 2.3 liters or 54 per cent. Maximum voluntary ventilation at 45 liters was 33 per cent of predicted value. The electrocardiogram was normal.

The patient was premedicated with meperidine 25 milligrams, promethazine 25 milligrams and atropine 0.6 milligrams intramuscularly one hour before operation. Lumbar puncture was performed with the patient in the sitting position using a $20 \mathrm{G}$ spinal needle at what was most likely the $L_{4-5}$ interspace. Tetracaine 10 milligrams was dissolved in 1 millimeter cerebrospinal fluid and 1.2 milliliters of dextrose 10 per cent solution and injected slowly. The level of analgesia obtained was $T_{10}$ prior to start of the operation, which proceeded uneventfully. There were no postoperative complications.

-From the Department of Anaesthesia, University of Saskatchewan and University Hospital, Saskatoon, Saskatchewan. 


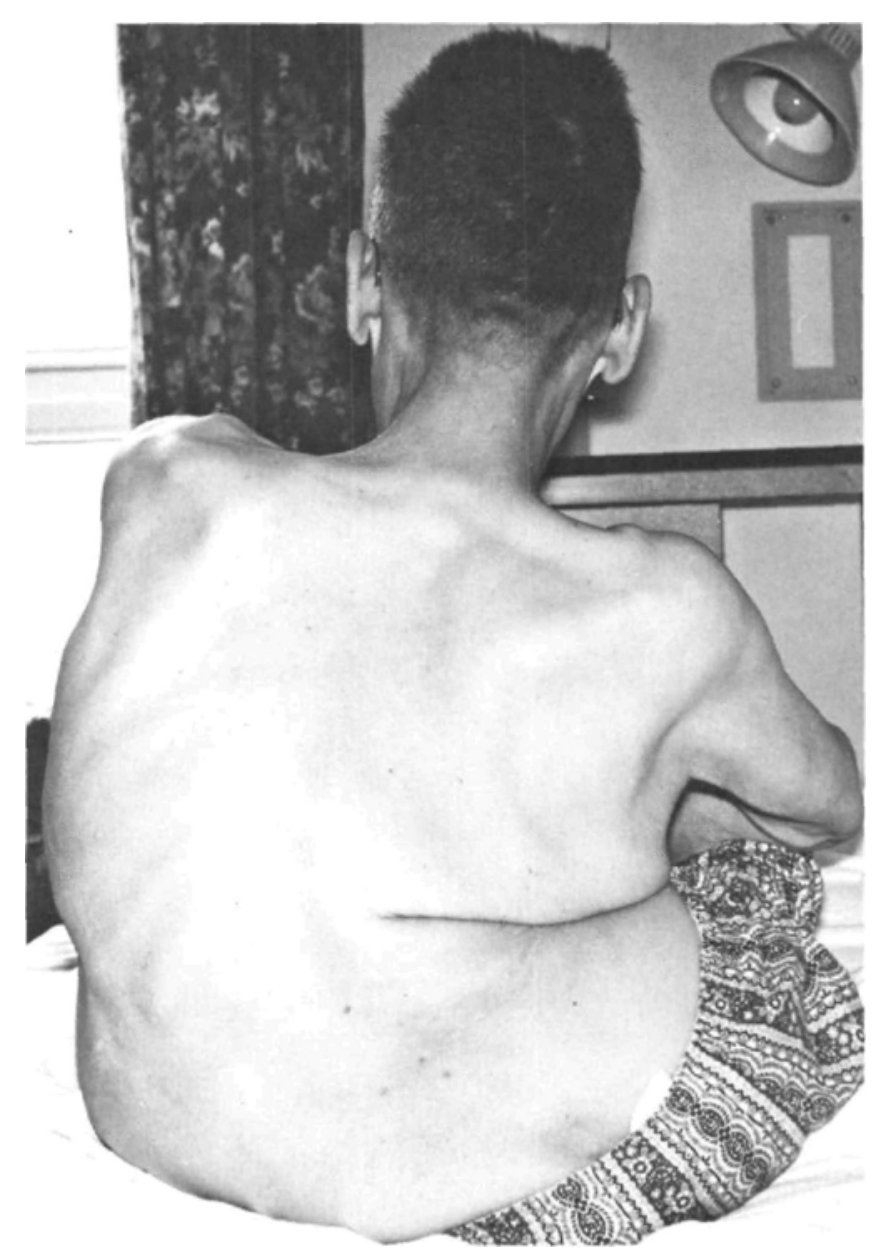

Figure 1.

\section{Discussion}

Relative contraindications to spinal anaesthesia are severe deformity of the spinal column and previous poliomyelitis with residual paralysis. Lund ${ }^{1}$ has stated that these conditions should probably not be considered as relative contraindications unless they are severe enough to render spinal anaesthesia virtually impossible. It is suggested that after careful evaluation of the patient with this type of problem, spinal anaesthesia can be most satisfactory.

\section{RÉSUMÉ}

Un malade de 62 ans présentant des contre-indications relatives à une anesthésie rachidienne, à savoir un problème neurologique (paraplégie post-polyomyélite) ainsi qu'une cypho-scoliose importante et devant subir une annuloplastie anale, a 


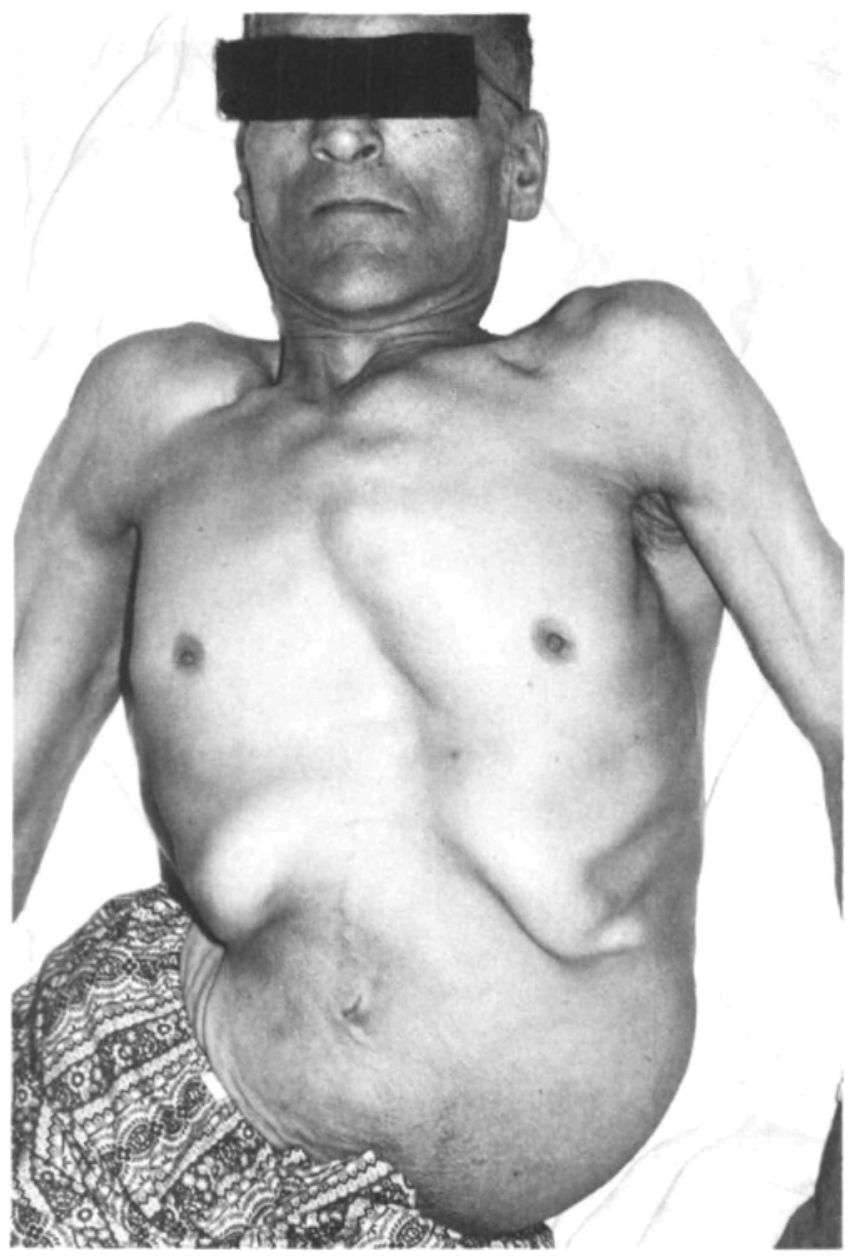

Figure 2.

été opéré sous rachi-anesthésie (Tétracaïne $10 \mathrm{mg}$ ), sans complications postopératoires.

Ce malade qui présentait un syndrome obstructif pulmonaire, et un diabète avait exprimé son désir de demeurer conscient durant son intervention.

Les auteurs suggèrent qu'une rachi-anesthésie peut être une méthode satisfaisante chez des patients présentant ce genre de problème.

\section{REFERENCE}

1. Lund, P.C. Principles and Practice of Spinal Anaesthesia, Springfield, Thomas (1971). 